\title{
A CAPACITY BUILDING FOR HIGHER EDUCATION ERASMUS+ PROJECT: STRATEGIC HUMAN RESOURCES MANAGEMENT FOR SOUTHEAST ASIAN UNIVERSITIES (HR4ASIA)
}

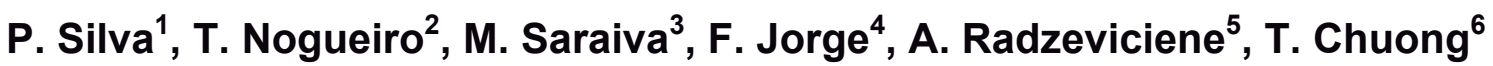 \\ ${ }^{1}$ Universidade de Évora (PORTUGAL) \\ ${ }^{2}$ Universidade de Évora e CEFAGE-UE (PORTUGAL) \\ ${ }^{3}$ Universidade de Évora e BRU-UNIDE/ISCTE-IUL (PORTUGAL) \\ ${ }^{4}$ Universidade de Évora e CICP (PORTUGAL) \\ ${ }^{5}$ Vilnius Gediminas Technical University (LITHUANIA) \\ ${ }^{6}$ Quy Nhon University (VIETNAM)
}

\begin{abstract}
The development and optimization of Higher Education Institutions (HEls) is becoming more and more important. Consequently, Human Resources Management (HRM) has gained greater prominence in the management of these institutions. Due to the complexity of academic contexts of HEls, HRM models need to be able to respond to new challenges. These challenges concern selection, motivation and development of their staff. Currently, especially in Southeast Asian countries, Human Resources approaches need to be more efficient and tailored to current labor and societal needs. In order to support Higher Education organizational changes in Southeast Asia, a consortium of 4 institutions from Europe (Spain, Portugal, Italy and Lithuania) and 8 from Asia (Vietnam, Cambodia, Laos and Thailand) lead by the University of Danang (Vietnam), applied to a Capacity Building for Higher Education project under the framework of the Erasmus+ Program. The project "Strategic Human Resources Management for Southeast Asian Universities" (HR4Asia) approved in 2016 and co-funded by the European Commission aims at contributing to Higher Education organizational reform in Southeast Asia by improving HRM at the target HEls from Cambodia, Lao PDR, Vietnam and Thailand. Each partner has well defined tasks according to the work packages established on the project. This research is focused on the competences that workers need to achieve to have a better performance in the institution. It was necessary to present and deconstruct, among others, the concepts of competence as capacity and competency as performance, to learn how to measure competencies and to manage competency and Human Resources. Staff involved in this project will be able to design and define the competencies model of the structures of each HEI to define the competency model per structure (mapping of organizational competencies and a model of competences of structures). This is one more step to achieve the following final goals: introduce in Southeast Asian HEls a scheme to developing and implementing innovative HRM approaches, paying attention to transversal and additional skills, such as communication and self-learning. Tailor-made dissemination activities addressing non-partner HEls, Ministries of Higher Education and other stakeholders will promote the project objectives, paving the way for its sustainability.
\end{abstract}

Keywords: Capacity Building for Higher Education, Erasmus+, Competencies and Competency, Human Resources Management, Southeast Asian Universities.

\section{INTRODUCTION}

The concept of 'competence' is not as straight as we can imagine since it is impossible to identify or impute a coherent theory or to arrive at a definition capable of accommodating and reconciling all the different ways that the term is used [1]. Competences are viewed as independent of the social and task-specific context in which performance occurs, since they are centred on the individual, yet 'skill level is a characteristic not only of a person but also of a context. People do not have competences independent of context' ([2], [1]).

In an attempt to situate competence in terms of socio-cultural practices [3] noted: "is disturbing in light of the strong bonds between identifying competencies and tying them to practice standards. These standards, once developed, find their way into practice through certification of people and processes, through accrediting agencies (public and private) for all sorts of educational programs, and through qualification examinations and licensure requirements....The commodification of competence into certifiable competencies privileges the KSA (knowledge, skills and attitudes) worldview, and turns 